\title{
Macular Choroidal Thickness in Patients with Ocular Hypertension as Assessed Using Enhanced Depth Imaging Optical Coherence Tomography
}

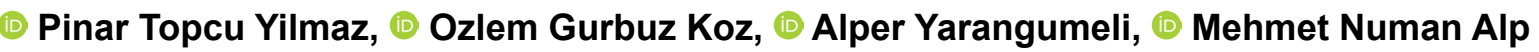 \\ Department of Ophthalmology, Health Sciences University, Ankara Numune Training and Research Hospital, Ankara, Turkey
}

\begin{abstract}
Objectives: The aim of this study was to evaluate the macular choroidal thickness (CT) in patients with ocular hypertension (OHT) using spectral domain optical coherence tomography (SD-OCT) and compare the results with healthy individuals.

Methods: Thirty eyes of 30 patients newly diagnosed with OHT and 24 eyes of 24 healthy controls were included in this cross-sectional study. After a detailed ophthalmological examination, macular CT was measured with enhanced depth imaging optical coherence tomography (EDI-OCT) (Cirrus HD-OCT, Carl Zeiss Meditec AG, Jena, Germany) at the fovea and at positions $500 \mu, 1000 \mu, 1500 \mu$ nasal and temporal to the fovea. The Mann-Whitney $U$ test was used to compare the CT measurements between groups. The correlation between the mean deviation, pattern standard deviation, and retinal nerve fiber layer thickness (RNFL) and CT was evaluated with the Spearman correlation coefficient. Statistical significance was accepted as $\mathrm{p}<0.05$.

Results: The mean CT in the OHT group was significantly thinner than that of the controls at locations $1000 \mu$ $(250.13 \pm 69.53 \mu$ vs $275.92 \pm 47.34 \mu ; p=0.02)$ and $1500 \mu(236.03 \pm 65.44 \mu$ vs $265.46 \pm 47.56 \mu ; p=0.009)$ temporal to the fovea. The CT at the other measurement points was also thinner in eyes with OHT, but the difference failed to reach statistical significance. A moderately negative correlation was detected between the mean deviation and CT at locations $1000 \mu(r=-0.42 ; p=0.03)$ and $1500 \mu(r=-0.44 ; p=0.02)$ temporal to the fovea There was a moderate correlation between the average RNFL thickness and CT at locations $500 \mu(r=0.44 ; p=0.03), 1000 \mu(r=0.42 ; p=0.04)$ and $1500 \mu(r=0.56$; $\mathrm{P}=0.005$ ) temporal to the fovea.

Conclusion: In the present study, the macular CT was thinner in patients with OHT and this thinning was statistically significant at the temporal macula. A longitudinal, prospective study involving multiple EDI-OCT measurements is required to further understand the relationship.

Keywords: Choroidal thickness, enhanced depth imaging optical coherence tomography, optical coherence tomography, ocular hypertension.
\end{abstract}

\section{Introduction}

Ocular hypertension (OHT) is a clinical condition characterized by elevated intraocular pressure (IOP), a normal visual field, and the absence of glaucomatous optic disc changes ( $I$, 2). If left untreated, the cumulative probability of developing primary open-angle glaucoma (POAG) at 5 years is reported to be $9.5 \%$ in these patients (3). While the benefits of treatment with $\mathrm{OHT}$ medications have been well-documented, the continued loss of visual function in some patients with controlled IOP supports the role of vascular and hemodynamic factors in the pathogenesis of glaucomatous optic neuropathy (4).

Choroidal circulation is responsible for more than $70 \%$

Address for correspondence: Pinar Topcu Yilmaz, MD. Ankara Numune Egitim ve Arastirma Hastanesi, Saglik Bilimleri Universitesi, Oftalmoloji Anabilim Dali, Ankara, Turkey

Phone: +90 5324555202 E-mail: ptopcu78@hotmail.com

Submitted Date: December 30, 2018 Accepted Date: April 09, 2019 Available Online Date: August 05, 2017

${ }^{\circ}$ Copyright 2019 by Beyoglu Eye Training and Research Hospital - Available online at www.beyoglueye.com OPEN ACCESS This work is licensed under a Creative Commons Attribution-NonCommercial 4.0 International License. 
of the blood flow within the eye, and is the major supplier of nutrients to the optic nerve head. Therefore, abnormal choroidal blood supply is considered a potential factor responsible for the development of glaucomatous optic neuropathy (5). Recent advancements in optical coherence tomography (OCT) technology have enabled researchers to detect choroidal changes more accurately (6). Choroidal thickness (CT) in glaucoma patients measured with spectral domain optical coherence tomography (SD-OCT) has been studied extensively in the ophthalmological literature. However, few reports have investigated CT in OHT patients $(7,8)$.

The purpose of this study was to evaluate the macular $\mathrm{CT}$ in the eyes of patients with OHT and healthy controls, and investigate the correlation between macular $\mathrm{CT}$, visual field mean deviation (MD), and retinal nerve fiber layer (RNFL) thickness in OHT patients.

\section{Methods}

A total of 30 patients diagnosed with OHT and 24 age- and gender-matched healthy individuals were included in this cross-sectional, observational study. The study protocol was approved by the Institutional Review Board of Ankara Numune Training and Research Hospital and adhered to the tenets of the Declaration of Helsinki. Informed consent was obtained from all of the participants prior to enrollment in this study. Patients with systemic diseases (diabetes mellitus, hypertension, hyperlipidemia, sleep apnea syndrome, congenital or acquired heart disease, etc.) or ocular conditions (amblyopia, refractive errors greater than \pm 3.0 diopters of spherical equivalence, ocular inflammation or trauma) that could affect CT measurements were excluded from the study.

All of the study participants underwent a detailed ophthalmological evaluation, including measurement of best corrected visual acuity, slit lamp biomicroscopy, diurnal IOP measurement at 2-hour intervals with a Goldmann applanation tonometer, central CT measurement with an ultrasonic pachymeter (IOPac Advanced Pachymeter, Heidelberg Engineering $\mathrm{GmbH}$, Heidelberg, Germany) and fundus examination. The diagnosis of OHT was made by 2 glaucoma specialists in the presence of untreated IOP $>21 \mathrm{mmHg}$ on 2 separate visits, normal Humphrey 30-2 visual field test, normal optic disc appearance without glaucomatous changes, and open anterior chamber angle determined with gonioscopy.

The choroid was imaged by an experienced technician using the enhanced depth imaging (EDI) system of the Cirrus HD-OCT (Carl Zeiss Meditec AG, Jena Germany). In order to avoid the diurnal variation in $\mathrm{CT}$, all of the OCT examinations were performed between 10:00 am and II:00 am. The $\mathrm{CT}$ was measured manually from the outer border of the hyperreflective line of the retinal pigment epithelium to the inner border of the chorioscleral interface at the fovea and at positions $500 \mu, 1000 \mu$, and $1500 \mu$ nasal and temporal to the fovea. Measurements were performed by an ophthalmologist (PTY) masked to the group of the subject at the time of measurement. Images with low quality in which the chorioscleral interface could not be distinguished were excluded from the study. Measurements from one eye were used for the analysis of CT measurements because of intereye correlation.

Statistical analysis was performed using SPSS Statistics for Windows, Version 17.0 (SPSS Inc., Chicago, IL, USA). Categorical variables were analyzed using the Pearson chisquare test. The Mann-Whitney $U$ test was used to compare the macular $\mathrm{CT}$ measurements in patients with $\mathrm{OHT}$ and healthy controls. Correlations between the MD, PSD, RNFL thickness, and CT were evaluated with the Spearman correlation coefficient. A p value of less than 0.05 was considered statistically significant.

\section{Results}

Thirty eyes of 30 patients newly diagnosed with $\mathrm{OHT}$ and 24 eyes of 24 healthy controls were included in this study. The mean age of patients with OHT was $53.3 \pm 8.7$ years and the mean age of healthy controls was $49.5 \pm 12$.I years. There was no statistically significant difference in the mean age $(p=0.2)$, gender $(p=0.7)$, or stands for spherical eqivalent $(p=0.6)$ of the 2 groups. Detailed clinical characteristics of the study groups can be found in Table $I$.

The CT at all measurement points was thinner in the OHT group compared with the healthy controls. This difference reached statistical significance at locations $1000 \mu$ $(250.13 \pm 69.53 \mu$ vs $275.92 \pm 47.34 \mu ; p=0.02)$ and $1500 \mu$ $(236.03 \pm 65.44 \mu$ vs $265.46 \pm 47.56 \mu ; p=0.009)$ temporal to the fovea (Table 2).

There was a moderate correlation between the mean RNFL thickness and CT at $500 \mu, 1000 \mu$, and $1500 \mu$ temporal to the fovea $(r=0.44, p=0.03 ; r=0.42, p=0.04 ; r=0.56$, $p=0.005$; respectively). The MD was negatively associated with CT measurements at locations $1000 \mu$, and $1500 \mu$ temporal to the fovea $(r=-0.42, p=0.03 ; r=-0.44, p=0.02$, respectively) (Table 3 ). There was no significant correlation between the PSD values and CT measurements.

\section{Discussion}

The etiopathology in glaucomatous neurodegeneration is multifactorial. Currently, elevated IOP and vascular dysregulation are accepted as the main risk factors for development and progression (4). Several histopathological and imaging studies have evaluated ocular blood flow in an attempt to uncover the ocular hemodynamics in glaucoma $(4$, 9). Fluorescein angiographic studies have shown circulatory defects in the optic disc, peripapillary choroid and retina 
Table I. Clinical characteristics of the study population

\begin{tabular}{|c|c|c|c|}
\hline & $\begin{array}{l}\text { Ocular hypertension } \\
\qquad(n=30)\end{array}$ & $\begin{array}{l}\text { Healthy controls } \\
\qquad(n=24)\end{array}$ & $\mathbf{p}$ \\
\hline Sex (male/female) & $14 / 16$ & $10 / 14$ & 0.7 \\
\hline Age (years) & $53.3 \pm 8.7$ & $49.5 \pm 12.1$ & 0.2 \\
\hline IOP $(\mathrm{mmHg})$ & $23.4 \pm 2.5$ & $15.1 \pm 2.7$ & $<0.001$ \\
\hline Refractive error (D) & $-0.16 \pm 0.72$ & $-0.20 \pm 0.53$ & 0.6 \\
\hline Central corneal thickness $(\mu)$ & $552.52 \pm 31.36$ & & \\
\hline$M D(d B)$ & $-1.3 \pm 1.2$ & & \\
\hline PSD (dB) & $1.9 \pm 0.9$ & & \\
\hline
\end{tabular}

D: Diopter; IOP: Intraocular pressure; MD: Mean deviation; PSD: Pattern standard deviation..

Table 2. Choroidal thickness in patients with ocular hypertension and healthy controls

\begin{tabular}{|c|c|c|c|}
\hline & $\begin{array}{l}\text { Ocular hypertension } \\
\qquad(n=30)\end{array}$ & $\begin{array}{l}\text { Healthy controls } \\
\qquad(n=24)\end{array}$ & $\mathbf{p}$ \\
\hline Subfoveal CT & $298.33 \pm 72.47$ & $308.92 \pm 49.11$ & 0.2 \\
\hline $500 \mu$ nasal CT & $265.57 \pm 62.11$ & $279.75 \pm 52.69$ & 0.3 \\
\hline $1000 \mu$ nasal CT & $251.67 \pm 61.01$ & $265.62 \pm 53.79$ & 0.3 \\
\hline I $500 \mu$ nasal CT & $229.07 \pm 52.62$ & $247.79 \pm 60.12$ & 0.4 \\
\hline $500 \mu$ temporal CT & $266.87 \pm 73.32$ & $283.33 \pm 51.53$ & 0.07 \\
\hline I000 $\mu$ temporal CT & $250.13 \pm 69.53$ & $275.92 \pm 47.34$ & 0.016 \\
\hline I500 $\mu$ temporal CT & $236.03 \pm 65.44$ & $265.46 \pm 47.56$ & 0.009 \\
\hline
\end{tabular}

Table 3. Correlation between choroidal thickness, mean deviation (MD) and average retinal nerve fiber layer thickness (RNFL)

\begin{tabular}{|c|c|c|c|c|}
\hline & \multicolumn{2}{|c|}{ MD } & \multicolumn{2}{|c|}{ Average RNFL thickness } \\
\hline & $\mathbf{r}$ & $\mathbf{p}$ & $\mathbf{r}$ & $\mathbf{p}$ \\
\hline Subfoveal CT & -0.24 & NS & 0.35 & NS \\
\hline $500 \mu$ nasal CT & -0.25 & NS & 0.25 & NS \\
\hline $1000 \mu$ nasal CT & -0.05 & NS & 0.22 & NS \\
\hline I $500 \mu$ nasal CT & -0.07 & NS & 0.03 & NS \\
\hline $500 \mu$ temporal CT & -0.29 & NS & 0.44 & 0.03 \\
\hline $1000 \mu$ temporal CT & -0.42 & 0.03 & 0.42 & 0.04 \\
\hline I500 $\mu$ temporal CT & -0.44 & 0.02 & 0.56 & 0.005 \\
\hline
\end{tabular}

CT: Choroidal thickness; MD: Mean deviation; RNFL: Retinal nerve fiber layer.

(I0). Marangoni et al. (I I) reported that subfoveal choroidal blood flow was reduced in patients with early glaucoma and suggested that diminished choroid blood flow could be a predictor of faster disease progression.

Recent advancements in OCT technology have enabled in vivo imaging of the choroid and led to a renewed inter- est in the choroidal changes of different disease states. A potential association between $\mathrm{CT}$ and glaucoma has been investigated in several studies. Bayhan et al. (12) found that the nasal choroid was thinner in patients with pseudoexfoliation glaucoma. Song et al. (13) evaluated peripapillary CT in open-angle glaucoma and detected significant choroidal thin- 
ning in the study population. Recently; Sacconi et al. (14) assessed CT in advanced open-angle glaucoma, and found that subfoveal CT and temporal CT were significantly reduced in the patient group. In contrast, other studies and meta-analyses have failed to demonstrate significant choroidal thinning in patients with open-angle glaucoma, normal-tension glaucoma, and healthy controls (I5-I8).

$\mathrm{OHT}$ is defined as high intraocular pressure with normal visual fields and without evidence of glaucomatous optic disc changes (2). The Ocular Hypertension Treatment Study demonstrated that the rate of progression to glaucoma was $9.5 \%$ in untreated patients and that early treatment was effective in the prevention of glaucoma onset in patients with OHT (I-3). Evaluation of changes in the ocular blood flow of OHT patients can provide clues about possible underlying factors that lead to development of glaucoma. Despite the large number of EDI-OCT studies of glaucoma, few have investigated the relationship between $\mathrm{CT}$ and $\mathrm{OHT}(7,8)$. Lamparter et al. (8) investigated peripapillary $\mathrm{CT}$ in patients with open-angle glaucoma and OHT. They found that the peripapillary CT was slightly greater in OHT, but age-adjusted comparisons between the groups indicated that this difference was only marginally significant $(p=0.059)$. Recently; Lin et al. (7) evaluated the macular choroid in OHT patients and found that macular CT was thinner in OHT patients; however, this thinning did not reach statistical significance. In the present study; patients with OHT had thinner choroids and this difference between the OHT and control groups was statistically significant in 2 locations: $1000 \mu$ and $1500 \mu$ temporal to the fovea. Furthermore, the $C T$ at these 2 locations showed a moderate correlation with $M D(r=-0.42, p=0.03$; $r=-0.44, p=0.02$, respectively) and RNFL thickness $(r=0.42$, $p=0.04 ; r=0.56, p=0.005$, respectively).

The major limitation of the present study is its crosssectional design. A prospective study could yield more information regarding a possible relationship between CT and progression to glaucoma. The sample size was also relatively small. The lack of automatic segmentation in the current OCT software of the Cirrus-HD OCT and manual measurement of the CT might have introduced some inaccuracy. However, previous studies have reported high intra- and inter-observer repeatability (19). Although we excluded patients with systemic hypertension, the absence of diastolic blood pressure measurements is another limitation of our study (20).

In conclusion; this is the second study to evaluate the macular CT in patients with OHT. We found thinner choroids in OHT patients, particularly at locations temporal to the fovea. Further studies with a larger number of patients and longitudinal follow-up are required to determine role of CT as a predictor of glaucoma development in OHT.

\section{Disclosures}

Ethics Committee Approval: Health Sciences University Ankara Numune SUAM Clinical Research Ethics Committee, January 17, 2018, no: 1698.

Peer-review: Externally peer-reviewed.

Conflict of Interest: None declared.

Authorship Contributions: Involved in design and conduct of the study (PTY, OGK, AAY, MNA); preparation and review of the study (PTY, OGK, AAY, MNA); data collection (PTY, OGK, AAY, MNA); and statistical analysis (PTY, OGK, AAY, MNA).

\section{References}

I. Kass MA, Heuer DK, Higginbotham EJ, Johnson CA, Keltner JL, Miller JP, et al. The Ocular Hypertension Treatment Study: a randomized trial determines that topical ocular hypotensive medication delays or prevents the onset of primary open-angle glaucoma. Arch Ophthalmol 2002;120:70I-13.[CrossRef]

2. Boey PY, Mansberger SL. Ocular hypertension: an approach to assessment and management. Can J Ophthalmol 20I4;49:489-96.

3. Gordon MO, Beiser JA, Brandt JD, Heuer DK, Higginbotham EJ, Johnson CA, et al. The Ocular Hypertension Treatment Study: baseline factors that predict the onset of primary open-angle glaucoma. Arch Ophthalmol 2002;120:7|4-20. [CrossRef]

4. Flammer J, Orgül S, Costa VP, Orzalesi N, Krieglstein GK, Serra LM, et al. The impact of ocular blood flow in glaucoma. Prog Retin Eye Res 2002;21:359-93. [CrossRef]

5. Goharian I, Sehi M. Is There Any Role for the Choroid in Glaucoma? J Glaucoma 2016;25:452-8. [CrossRef]

6. Spaide RF, Koizumi H, Pozzoni MC. Enhanced depth imaging spectral-domain optical coherence tomography. Am J Ophthalmol 2008; I46:496-500. [CrossRef]

7. Lin Z, Huang S, Huang P, Guo L, Bian H, Zhong Y. Analysis of choroidal thickness in ocular hypertensive patients using enhanced depth imaging optical coherence tomography. Lasers Med Sci 2018;33: I II-121. [CrossRef]

8. Lamparter J, Schulze A, Riedel J, Wasielica-Poslednik J, König J, Pfeiffer N, et al. Peripapillary Choroidal Thickness and Choroidal Area in Glaucoma, Ocular Hypertension and Healthy Subjects by SD-OCT. Klin Monbl Augenheilkd 20I5;232:390-4. [CrossRef]

9. Banitt M. The choroid in glaucoma. Curr Opin Ophthalmol 2013;24:125-9. [CrossRef]

10. Schwartz B. Circulatory defects of the optic disk and retina in ocular hypertension and high pressure open-angle glaucoma. Surv Ophthalmol 1994;38 Suppl:S23-34. [CrossRef]

I I. Marangoni D, Falsini B, Colotto A, Salgarello T, Anselmi G, Fadda $A$, et al. Subfoveal choroidal blood flow and central retinal function in early glaucoma. Acta Ophthalmol 2012;90:e288-94. [Crossee]

12. Bayhan HA, Bayhan SA, Can I. Evaluation of the Macular Choroidal Thickness Using Spectral Optical Coherence Tomography in Pseudoexfoliation Glaucoma. J Glaucoma 2016;25:184-7. [CrossRef] 
13. Song YJ, Kim YK, Jeoung JW, Park KH. Assessment of OpenAngle Glaucoma Peripapillary and Macular Choroidal Thickness Using Swept-Source Optical Coherence Tomography (SSOCT). PLoS One 2016; I I:e0I57333. [CrossRef]

14. Sacconi R, Deotto N, Merz T, Morbio R, Casati S, Marchini G. SD-OCT Choroidal Thickness in Advanced Primary Open-Angle Glaucoma. J Glaucoma 2017;26:523-527. [CrossRef]

15. Wang W, Zhang $X$. Choroidal thickness and primary open-angle glaucoma: a cross-sectional study and meta-analysis. Invest Ophthalmol Vis Sci 20I4;55:6007-I4. [CrossRef]

16. Zhang Z, Yu M, Wang F, Dai Y, Wu Z. Choroidal Thickness and Open-Angle Glaucoma: A Meta-Analysis and Systematic Review. J Glaucoma 2016;25:e446-54. [CrossRef]

17. Mwanza JC, Sayyad FE, Budenz DL. Choroidal thickness in unilateral advanced glaucoma. Invest Ophthalmol Vis Sci 20I2;53:6695-70I. [CrossRef]

18. Mwanza JC, Hochberg JT, Banitt MR, Feuer WJ, Budenz DL. Lack of association between glaucoma and macular choroidal thickness measured with enhanced depth-imaging optical coherence tomography. Invest Ophthalmol Vis Sci 20I I;52:3430-5. [CrossRef]

19. Rahman W, Chen FK, Yeoh J, Patel P, Tufail A, Da Cruz L. Repeatability of manual subfoveal choroidal thickness measurements in healthy subjects using the technique of enhanced depth imaging optical coherence tomography. Invest Ophthalmol Vis Sci 20I I;52:2267-7I. [CrossRef]

20. van Setten GB, Trost A, SchrödI F, Kaser-Eichberger A, Bogner $B$, van Setten $M$, et al. Immunohistochemical Detection of CTGF in the Human Eye. Curr Eye Res 2016;41:157I-1579. 